\title{
MIGRATION: CAUSES AND TRENDS WITH SPECIAL REFERENCE TO RURAL-URBAN MIGRATION IN INDIA
}

\author{
Devaraj Dutta \\ Freelance Scholar
}

\begin{abstract}
"Migration is the barometer of changing socio-economic and political conditions at the national and international levels" (Razi, S., p. 3, 2014). There are various factors which has compelled people to migrate from one place to another. However, these factors may vary from country to country and from place to place. It may also vary from state to state within a country. In a developing country like India, migration mostly take place due to some factors like poverty, unemployment, natural calamities and underdevelopment at the place from where people migrate to some other places. In India internal mobility is still seem to be very critical to the livelihoods of many people, especially those living in rural parts of the country. People from rural areas migrate to nearby urban centres or cities mostly in search of better earning opportunities. It is expected that the percentage of urban population in India which was only 17 per cent of the total population in 1951 would jump to around 42.5 per cent of the total population by 2025 (Razi, S., 2014). The present paper, therefore, is an attempt to study the various causes and trends of migration with a special focus on rural-urban migration in India.
\end{abstract}

Key words: Migration, Rural-Urban Migration, Causes, Trends, India.

Cite this Article: Devaraj Dutta, Migration: Causes and Trends with Special Reference to Rural-Urban Migration in India. International Journal of Management, 11(12), 2020, pp 92-96.

https://iaeme.com/Home/issue/IJM?Volume=11\&Issue $=12$

\section{INTRODUCTION}

"Migration is the barometer of changing socio-economic and political conditions at the national and international levels". "The history of migration is the history of people's struggle to survive and to prosper, to escape insecurity and poverty, and to move in response to opportunity" (Razi, S., 2014, p. 3). There are a number of factors which has compelled people to migrate from one place to another. However, from country to country and from place to place it may differ. Again, it may also vary from state to state within a country. Factors such as poverty and starvation, unemployment, low productivity, failure of crop, landlessness, poor 
education \& medical care, lack of credit facilities mainly found in rural areas largely contribute towards rural-urban migration (Mohapatra, A. K., 2014, p.18). In a developing country like India, migration mostly take place due to some factors like poverty, unemployment, natural calamities and underdevelopment at the place (i.e., the place of origin) from where people migrate to some other places. "Migration in developing countries like India is still viewed as a survival strategy" (Razi, S., p. 3, 2014). In India internal mobility is still seem to be very critical to the livelihoods of many people, especially those living in rural parts of the country. It is expected that the percentage of urban population in India which was only 17 per cent of the total population in 1951 would jump to around 42.5 per cent of the total population by 2025 (Razi, S., 2014).

It is to be noted that in India, rural to urban migration is caused due to push and pull factors taken together. "But various research works carried out by scholars from time to time; pointed out that the cause of migration is not same for male to female and skilled to unskilled labour, educated to uneducated person and precisely it depends upon other characteristics of demography too" (Mohapatra, A. K., 2014, p. 18). According to Hassan and Khan (2014), "India is one of the most physically, socially and culturally diversified nation, consequently, regional disparities in the level of socio-economic development are quite striking in the country" (Hassan \& Khan, 2014, p. 32). As a result of this, there is the migration of people from culturally and economically deprived regions to the economically developed or culturally rich areas (Hassan \& Khan, 2014).

In the paper "Rural Distress and Rural Migration" the author Shahin Razi has stated that in India, 68.9 per cent of the population lives in 6.40 lakhs villages. According to him, "the share of agriculture to overall GDP in India has come down to 14 per cent while 66.2 per cent of rural males and 81.6 per cent of rural females are engaged in agriculture as cultivators or labourers" (Razi, S., 2014, p. 4). He is of the view that people from rural areas still migrate to urban areas in search of better employment opportunities (Razi, S., 2014, p. 4). As per an estimate, every year 2 million (approximately) people are shifting from rural to urban areas and 22 million (approximately) people have migrated from rural to urban areas since 2001 (Razi, S., 2014, p. 4).

\section{CAUSES OF MIGRATION}

There are various causes of migration of people from rural to urban centres and vice versa or from one region to another. Some of these are as mentioned below (Razi, S., 2014, p. 5):

- Social conflicts and social tension

- Gap in civilization/culture

- Law and Order situation

- Inequalities in the available social and economic opportunities and other amenities of life between groups of people and or sectors

- Income maximization

- Inequitable distribution of benefits of economic development

- Social mobility and social status aspirations

- Residential satisfaction

- Friend and family influences

- Desire for attaining lifestyle, performance and enjoyment. 


\section{Devaraj Dutta}

\section{RURAL-URBAN MIGRATION: SOME EMERGING TRENDS}

- The migration rate in the urban areas (35\%) was far higher than the migration rate in the rural areas $(26 \%)$.

- In both rural and urban areas, the magnitude of male migration rate was far lower than female migration rate. Nearly 48 per cent of the females in rural areas were migrants while the male migration rate was only 5 per cent. Against this, the male migration rate in the urban areas was nearly 26 per cent compared to female migration rate of 46 per cent.

- 91 per cent of the migrants in the rural areas had migrated from the rural areas and 8 per cent had migrated from the urban areas. On the other hand, nearly 59 per cent of the migrants among the migrants in the urban areas, had migrated from the rural areas and 40 per cent from urban areas.

- In both rural and urban areas, the most prominent reason for female migration was marriage. For 91 per cent of rural female migrants and 61 per cent of the urban female migrants the reason of their migration was marriage.

- In both rural and urban areas, the reason for migration for male migrant was dominated by employment related reasons. Nearly 29 per cent of rural male migrants and 56 per cent of urban male migrants had migrated due to this particular reason (Razi, S., 2014, p. 5).

\section{FACTORS RESPONSIBLE FOR RURAL MIGRATION}

There are many different factors which are responsible for migration of rural people to urban areas. Some of these are as discussed under (Kumar, P., 2014, p. 7-8):

\subsection{Population Pressure}

Today, due to the growth of population the pressure on our natural resources is increasing. In the rural areas this growth of population limits the already limited opportunities and resources. "More population means more and more peoples have to share the limited resources available with the rural families" (Kumar, P., 2014, p. 7). This also forces rural people to migrate to such places which they consider as safe destinations.

\subsection{Decreasing per capita availability of land}

The growth of population has led to the fragmentation of land as a result of which the per capita availability of land has decreased to a large extent. There are more than eight per cent farmers who are now marginal and small farmers. Such small holdings, today, have become uneconomical. It has compelled the farming community to search for other alternative sources of livelihood. This has also led to an increase in the migration of rural people to urban centers.

\subsection{Climate refugees}

In one of the reports, Dr. Thomas Fingar, Deputy Director of National Intelligence for Analysis and Chairman of the National Intelligence Council Current Research in Asia has stated that South, Southeast and East Asia will face risks of reduced agricultural productivity as large parts of the region face increased risk of floods and droughts. By 2025, cereal crop production will decrease 2.5-10 per cent.

It may be noted here that the credit for identifying migration due to climate change goes to Jodi Jacobson. In the coming decades the number of people who will migrate to other places 
to save themselves from the harsh extremities of weather (due to increasing temperature) will be more than from any other type of migration.

\subsection{Lack of livelihood opportunities}

Lack of livelihood opportunities in rural areas is another major factor which has compelled rural people to migrate to their nearest urban centers. Again, the absence of good schools, health care facilities, financial institutions, inaccessibility and suitable markets are some other factors which have also largely contributed towards migration of people from rural areas to urban centers.

\subsection{Improvement in communication and transport facilities}

Today the migration of rural people to urban areas has become very easy due to the development of communication and modern transport facilities. Nowadays people can easily access those areas which once were inaccessible and beyond reach. People from rural areas (whenever they have off season), migrate to urban areas for earning and then return back with the start of sowing season. Such type of seasonal and circular (also known as cyclical, oscillatory) migration is seem to be common among poor people across India.

\subsection{Employment}

Most of the people from rural parts of India also migrate to cities in search of employment in various types of industries. Because in urban areas there are many different types of industrial establishments which have the capacity to provide employment opportunities to a large number of people.

\section{CHECKING RURAL MIGRATION}

"Rural migration is still largely a survival; or a subsistence strategy" (Kumar, P., 2014, p. 10). In view of the above the following strategies can be employed in order to check migration effectively (Kumar, P., 2014, p. 10):

\subsection{Providing Urban Facilities in Rural Areas (PURA)}

In India it is due to various factors such as lack of livelihood opportunities, modern amenities and services necessary for decent living in rural areas result in a sense of deprivation and dissatisfaction amongst a large section of people. This has led to the migration of rural people to urban areas. From time to time, the government has, in the past, launched several schemes in order to address these issues. However, despite these schemes, a large section of people still migrates from rural areas to urban centers (Sharma, 2015). Keeping this in mind former Indian President Sh. A. P. J. Abdul Kalam put forwarded the idea of PURA to provide rural people with urban facilities. The basic idea of PURA is to provide them with drinking water facilities, sanitation, village streets, drainage, solid waste management, skill development and many other facilities.

\subsection{Providing Suitable Wage Employment Opportunities:}

If rural people are provided with suitable livelihood opportunities then they will never think of leaving their homes in search of better employment opportunities. Various research studies have already proved this. For example, the Mahatma Gandhi National Rural Employment Guarantee Act has been providing 100 men days of work to each family in the rural areas. 


\section{Devaraj Dutta}

\subsection{Making Agriculture Remunerative:}

Today in many parts due to the rising costs of cultivation and a declining return, agriculture as a major mainstream livelihood activity is now being perceived as a failure. It is, therefore, important to make suitable interventions so as to make agriculture more profitable.

\section{CONCLUDING REMARKS}

Migration and related issues are the major areas of research today. However, despite conducting various research studies on the field there remains a number of issues related to migration which have not been addressed properly till now. Studies shows that the economic factor has always remained as the major cause and concern behind the migration. It is, therefore, very necessary to give top most priority on the agriculture and non-farm sector at rural landscape, in order to control migration. Moreover, to control rural to urban migration the government should provide all kind of support to the rural migrants for getting their livelihoods and basic amenities for a descent standard of living at the rural areas (Mohapatra, A. K., 2014).

\section{REFERENCES}

[1] Hassan., T \& Khan., J. S. (2014). Repercussions of migration on rural migrants: A case study. Kurukshetra, 62 (11), 32-34.

[2] Kumar, P. (2014). Consequences of rural migration. Kurukshetra, 62 (11), 7-10.

[3] Mohapatra, A. K. (2014). Rural-urban migration in India-A critical review. Kurukshetra, 62 (11), 18-21.

[4] Razi, S. (2014). Rural distress and rural migration, Kurukshetra, 62 (11), 3-6.

[5] Sharma, A. (2015). PURA: Rural urban linkage in India. Kurukshetra, 63 (4), 24-27.

\section{AUTHOR'S PROFILE}

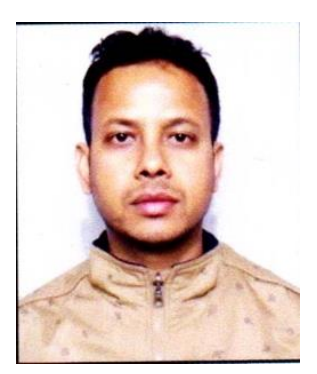

Devaraj Dutta, son of Lt. Tankeswar Dutta and Mrs. Dimbeswari Bhuyan Dutta, is a resident of the district Lakhimpur, Assam, India. He received his Bachelor's Degree in Political Science from Cotton College, Gauhati, Assam, India and the Master's Degree from Gauhati University, Assam, India. Recently he has completed his M. Phil in Political Science. He poses 7 years of teaching experience. He has presented 10 research papers in national level seminars. He has also published 10 articles/research papers in various journals (national and international) and research books. Furthermore, Mr. Dutta has participated in a number of national and state level workshops. His areas of interest include Human Rights, Public Administration, Rural Development, Gender Studies etc. 